\title{
Clinical, Surgical and Outcome Predictive Factor Analysis of Operated Acute Subdural Hematoma Cases: A Retrospective Study of 114 Operated Cases at Tertiary Centre
}

\author{
Rahul Singh ${ }^{1, \odot}$ Ravi Shankar Prasad ${ }^{1, \odot} \quad$ Kulwant Singh ${ }^{1, \odot} \quad$ Anurag Sahu ${ }^{1, \odot} \quad$ Nityanand Pandey
}

${ }^{1}$ Department of Neurosurgery, Institute of Medical SciencesBanaras Hindu University (IMS-BHU), Varanasi, India
Address for correspondence Ravi Shankar Prasad, MCh Neurosurgery, Associate Professor and Head, Department of Neurosurgery, Institute of Medical Sciences-Banaras Hindu University (IMS-BHU), Varanasi, India (e-mail: rsprasadbhuhodneurosurgery@gmail.com).

Indian J Neurosurg 2022;11:128-135

\begin{abstract}
Keywords

- Acute subdural hematoma

- outcome predictive factors

- operated acute SDH

- Glasgow outcome score

Objective To analyze clinical, surgical and outcome predictive factors of operated acute subdural hematoma (SDH) cases for prognostication and surgical outcome prediction. Material and Methods This retrospective study includes 114 patients operated for acute SDH in the Department of Neurosurgery of IMS BHU, Varanasi, India, a tertiary care center, between 1 August 2018 and 1 November 2019. Each patient was evaluated for age, sex, mode of injury, localization of hematoma, clinical presentation, comorbidity, severity of injury, best motor response, CT findings, and Glasgow outcome scale (GOS) at discharge. The outcome was also evaluated by further making a dichotomized group using GOS in death/dependent (1-3) versus independent (4-5). Statistical tests were done using the GraphPad Prism version 8.3.0.

Results The most common age group operated upon in this study was the 40 to 60 years age group ( $n=45,39.48 \%$ ). Males were $78 \%$ with male to female ratio of 3.56:1. The most common clinical presentation was altered sensorium (98.25\%). The most common comorbidity was hypertension ( $n=32,28.07 \%)$. GCS at admission, severity of injury, pupillary changes, and best motor response $(p<0.0001)$ were significantly associated with surgical outcome.

Conclusion GCS at admission, severity of injury, pupillary changes, and best motor response were significantly $(p<0.05)$ associated with surgical outcome. Age and gender of patients were not found to be significantly associated.
\end{abstract}

\section{Introduction}

Acute subdural hematoma (aSDH) constitutes $50 \%$ to $60 \%$ of all subdural hematomas (SDHs). ${ }^{1}$ They are mostly traumatic ${ }^{2}$ but may occur spontaneously (or after minor trauma) in patients on chronic anticoagulation therapy, bleeding diathesis, ${ }^{3}$ or after rupture of a posterior communicating artery aneurysm. ${ }^{4}$ Clinically, an acute SDH occurs within 3 days of injury.

Classically, SDHs are caused by rupture of dural bridging veins that lie in subdural space and drain cortical blood

published online May 25, 2021
DOI https://doi.org/

$10.1055 / \mathrm{s}-0040-1719201$ ISSN 2277-954X. into dural sinuses ( - Fig. 1). Acute SDH may also result from bleeding from superficial cortical vessels. ${ }^{1}$ It may have an underlying burst lobe (complex of SDH and damaged brain cortex). The associated brain damage is mainly caused by local ischemia due to mass effect, direct brain injury, or hampered venous outflow.

Classically, acute SDH on noncontrast CT head presents as a crescent-shaped homogeneously hyperdense extra-axial collection, spreading diffusely over the brain convexity of affected hemisphere. It is hyperdense relative to the cortex. (-Fig. 2). 


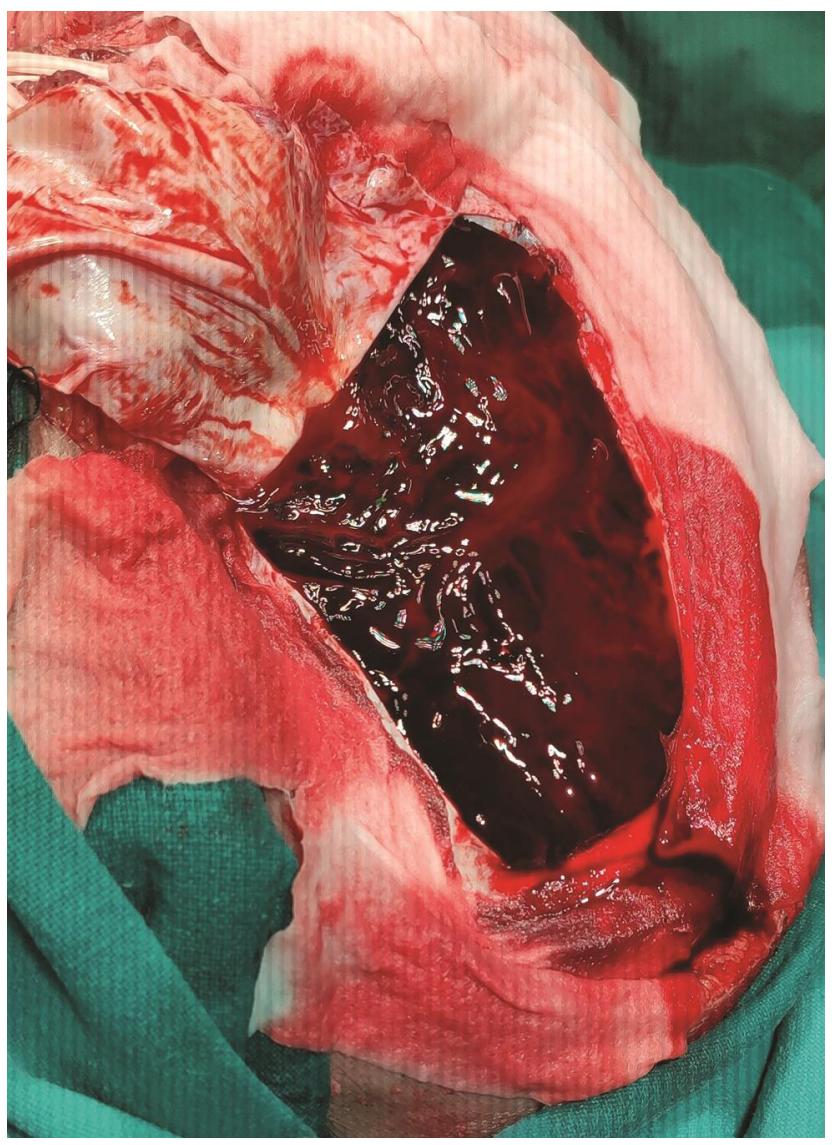

Fig. 1 Intraoperative image of acute subdural hematoma (SDH) after frontotemporoparietal craniectomy and incising dura. Note the hematoma of acute SDH overlying brain surface

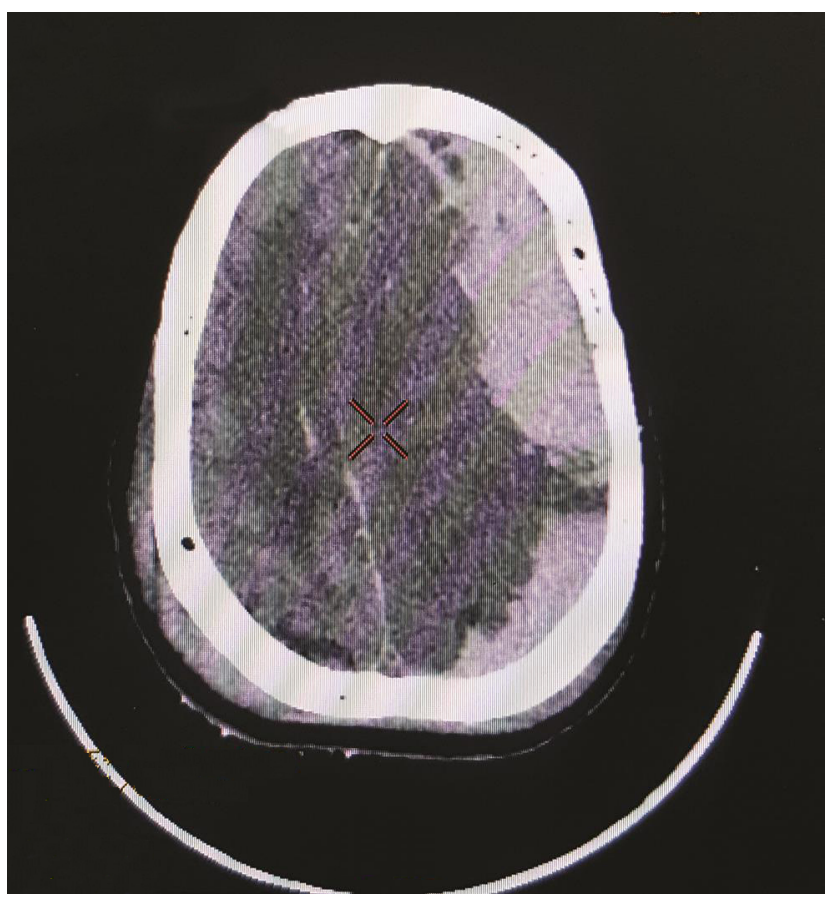

Fig. 2 Axial section of noncontrast CT scan brain showing crescent-shaped homogeneously hyperdense extra-axial collection in left frontotemporoparietal region.
Rapid deterioration may occur, especially if cortical arteries are ruptured. Prognosis is usually poor in patients of acute $\mathrm{SDH}$, warranting rapid hematoma evacuation and stopping the cause of bleeding. ${ }^{5}$

Ischemic cerebral damage is a very critical prognosticating factor in the pathology of SDH and may be due to the mass effects of the hematoma and raised intracranial pressure (ICP), leading to compromised cerebral perfusion pressure (CPP). Timely clot evacuation (within 4 hours) generally results in significantly improved neurological outcome. ${ }^{6}$ The accompanying brain damage besides acute SDH is responsible for poor neurological function after injury.

Operative outcome of acute SDH depends on multitude of factors, namely, multiple comorbidities, coexisting brain injury, cerebral ischemia, antithrombotic therapy, geriatric age group, etc. A correct identification of outcome predictive factors is crucial for appropriate neurosurgical intervention.

In this article, we analyzed the clinical, surgical, and outcome predictive factors of operated cases of acute SDH at our tertiary care center. Most of the studies done earlier are on both conservative and surgically managed patients. In this study, we studied only the operated cases of acute SDH to get their clinical picture and outcome predictive factors for better management of neurosurgical patients.

\section{Materials and Methods}

This retrospective study includes 114 patients who underwent surgery for acute SDH in an emergency setup in the Department of Neurosurgery of IMS BHU, Varanasi, India, a tertiary care center, between 1 August 2018 and 1 November 2019.

This is a retrospective cohort study in two phases: a cross-sectional phase where the patients included in the sample were evaluated for the following described variables, and a follow-up phase until hospital discharge or death. Each of the patients were evaluated in terms of age, sex, mode of injury, localization of hematoma, clinical presentation, comorbidity, severity of injury, best motor response, CT findings, and Glasgow outcome scale (GOS) at discharge. The outcome was also evaluated by further making a dichotomized group using GOS in death/dependent (1-3) versus independent (4-5).

The inclusion criteria were all patients admitted to the trauma center, IMS BHU, Varanasi, India and submitted to decompressive craniectomy and surgical evacuation of acute SDH in the Neurosurgery Department between 1 August 2018 and 1 November 2019. Patients who underwent surgery in the first 4 hours of reporting to trauma center were included in the study. The exclusion criterion was unknown data concerning the study variables and conservatively managed acute SDH cases and those who did not give consent for surgery. One hundred fourteen patients were included in the study.

Surgical technique used was trauma flap creation, followed by decompressive craniectomy and acute SDH evacuation and then lax duraplasty using pericranial graft in watertight fashion, so that a dural expansion is obtained 
for potential brain parenchyma swelling. Bone was placed in subcutaneous abdominal pouch, which was later utilized for autologous cranioplasty. In patients on anticoagulation therapy, fresh frozen plasma was used to correct the international normalized ratio (INR), and in those under antiplatelet therapy, pools of platelets were used according to surgeon preference. Postoperative ICU care was provided. Informed consent was taken from all operated cases by patient or patient attendants (in cases in which patient was not able to consent, namely, poor Glasgow coma scale [GCS] score)

Data was collected retrospectively by analyzing medical and surgical records of 114 operated patients submitted in the medical record department, IMS BHU, Varanasi, India, between 1 August 2018 and 1 November 2019. Statistical tests were done using GraphPad Prism version 8.3.0 software. For dichotomous evaluation, the Pearson and Fisher Chi-square test and unpaired $t$-test were used according to data analyzed. For percentage or proportion data, Chi-square test was used along with unpaired $t$-test and one-way ANOVA test for testing significance level for difference of means. $p<0.05$ was deemed statistically significant.

\section{Results}

\section{Incidence of Age}

In the present study, the largest number of patients operated for acute SDH belong to the age group of 40 to 60 years ( $n=45,39.48 \%$ ), followed by the 20 to 40 years age group ( $n=41$, $35.96 \%)$, 60 years $(n=24,21.05 \%)$ and $<20$ years $(n=4,3.51 \%)$, respectively ( - Table 1 ). Out of 114 patients, 89 patients (78\%) were males and 25 patients (22\%) were females (-Table $\mathbf{1}$ ). Male to female ratio is $3.56: 1$.

\section{Mode of Injury}

Mode of injury in majority of patients in this study was road traffic accidents (RTA), accounting for 93 patients $(81.58 \%)$; 15 patients $(13.16 \%)$ suffered a fall from height, four patients (3.51\%) experienced assault, and two patients (1.75\%) suffered a spontaneous fall following trivial trauma ( - Table $\mathbf{1}$ ).

\section{Severity of Injury}

In terms of severity of head injury, which is expressed in terms of GCS scores, majority of patients ( $n=86,75.44 \%$ ) were afflicted with a severe head injury and had GCS score of 3 to 8 . Twenty-one patients (18.42\%) were afflicted a moderate head injury and had GCS score of 9 to 13, and seven patients were afflicted with a mild head injury (6.14\%) and had GCS score of 14 to 15 (- Table 1 ).

\section{Best Motor Response}

In this study, the most common best motor response was M2 ( $n=30,26.32 \%)$ followed by M5 $(n=28,24.56 \%)$, M3 ( $n=28$, $24.56 \%), \operatorname{M} 4(n=21,18.42 \%), \operatorname{M} 1(n=5,4.39 \%)$ and M6 $(n=2$, 1.75\%), respectively ( - Table $\mathbf{1}$ ).

\section{Clinical Presentation}

In this study, most of the patients presented with altered sensorium ( $n=112,98.25 \%)$. Lucid interval was present in two patients(1.75\%), bradycardia in 10 patients(8.77\%), headache/ vomiting in 32 patients(28.07\%), neurodeficit in 30 patients (26.31\%), anisocoria in 20 patients (17.54\%), bilateral pupillary changes in 28 patients(24.56\%), Battle's sign in 10 patients (8.77\%), hemotympanum in four patients (3.51\%), black eye in 13 patients $(11.40 \%)$, and hypoxia or hypotension in five patients $(4.39 \%)$ (-Table 1 ).

\section{Site of aSDH}

In the present study, the most common site of acute SDH was frontotemporoparietal ( $n=92,80.70 \%$ ), followed by frontotemporal ( $n=9,7.89 \%)$, temporoparietal $(n=3,2.63 \%)$, frontoparietal ( $n=3,2.63 \%)$, temporal $(n=2,1.75 \%)$ and parietal $(n=1,0.88 \%)$, respectively (-Table 2 ).

\section{Side of aSDH}

In our study, out of 114 patients, 65 patients (57\%) had acute SDH on left side, 49 patients (43\%) on right side (-Table 2 ).

\section{CT Findings}

CT brain findings of acute SDH and its effects are as follows: Clot thickness less than $10 \mathrm{~mm}$ was found in two patients (1.75\%), 10 to $15 \mathrm{~mm}$ was found in 28 patients (24.56\%), 15 to $20 \mathrm{~mm}$ was found in 49 patients (42.98\%), and more than or equal to $20 \mathrm{~mm}$ was found in 35 patients (30.70\%).

Midline shift was noted in 105 patients (92.10\%). Brain herniation was present in 66 patients (57.89\%) (-Table 2 ).

\section{Comorbidity}

In the present study, comorbidities associated with acute SDH patients were hypertension ( $n=32,28.07 \%$ ), diabetes ( $n=20,17.54 \%)$, on anticoagulant therapy $(n=20,17.54 \%)$, respiratory disease $(n=20,17.54 \%)$, cardiovascular disease ( $n=14,12.28 \%$ ), dementia ( $n=6,5.26 \%)$, stroke $(n=5,4.38 \%)$, psychiatry illness $(n=3,2.63 \%)$, seizure disorder $(n=2$, $1.75 \%)$, previous head injury ( $n=2,1.75 \%)$, gastrointestinal disorders $(n=1,0.88 \%)$, and cancer $(n=1,0.88 \%)$ (- Table 1).

\section{Glasgow Outcome Score (GOS)}

In the present study, 30 patients $(26.32 \%)$ recovered well with GOS score of 5 (good recovery), 24 patients (21.05\%) had moderate disability with GOS $=4,23$ patients $(20.17 \%$ ) had severe disability with GOS $=3,25$ patients $(21.93 \%)$ were in persistent vegetative state $\mathrm{GOS}=2$, and 12 patients $(10.53 \%$ ) was dead with GOS $=1$ ( - Table 3 ).

\section{Variables of Operated Acute SDH cases-Glasgow Outcome Scale (GOS)}

In this study, we found GCS at admission $(p<0.0001)$, severity of injury $(p<0.0001)$, pupillary changes $(p<0.0001)$, and best motor response $(p<0.0001)$ were significantly $(p<0.05)$ associated with outcome following surgery for acute SDH. In contrast, age and gender of patients were not found to be significantly associated with outcome following surgery. (-Table 4) 
Table 1 Age, sex distribution, mode of injury, severity of injury, best motor response, clinical presentation, and comorbidities

\begin{tabular}{|c|c|c|}
\hline & Number of patients & $\%$ \\
\hline \multicolumn{3}{|l|}{ Age in years } \\
\hline$<20$ & 4 & 3.51 \\
\hline $20-40$ & 41 & 35.96 \\
\hline $40-60$ & 45 & 39.48 \\
\hline$>60$ & 24 & 21.05 \\
\hline Total & 114 & 100 \\
\hline \multicolumn{3}{|l|}{ Sex } \\
\hline Male & 89 & 78 \\
\hline Female & 25 & 22 \\
\hline \multicolumn{3}{|l|}{ Mode of injury } \\
\hline RTA & 93 & 81.58 \\
\hline Assault & 4 & 3.51 \\
\hline Fall from height & 15 & 13.16 \\
\hline Spontaneous/trivial trauma & 2 & 1.75 \\
\hline \multicolumn{3}{|l|}{ Severity (GCS) } \\
\hline Mild (14-15) & 7 & 6.14 \\
\hline Moderate (9-13) & 21 & 18.42 \\
\hline Severe $(3-8)$ & 86 & 75.44 \\
\hline \multicolumn{3}{|l|}{ Best motor response } \\
\hline M6 & 2 & 1.75 \\
\hline M5 & 28 & 24.56 \\
\hline M4 & 21 & 18.42 \\
\hline M3 & 28 & 24.56 \\
\hline M2 & 30 & 26.32 \\
\hline M1 & 5 & 4.39 \\
\hline \multicolumn{3}{|l|}{ Signs/symptoms } \\
\hline Lucid interval & 2 & 1.75 \\
\hline Bradycardia & 10 & 8.77 \\
\hline Headache/vomiting & 32 & 28.07 \\
\hline Altered sensorium & 112 & 98.25 \\
\hline Neurodeficit & 30 & 26.31 \\
\hline Anisocoria & 20 & 17.54 \\
\hline Pupillary changes (B/L) & 28 & 24.56 \\
\hline Black eye & 13 & 11.40 \\
\hline Battle sign & 10 & 8.77 \\
\hline Hemotympanum & 4 & 3.51 \\
\hline Hypoxia/hypotension & 5 & 4.39 \\
\hline \multicolumn{3}{|l|}{ Medical history } \\
\hline Hypertension & 32 & 28.07 \\
\hline On anticoagulant therapy & 20 & 17.54 \\
\hline Cardiovascular disease & 14 & 12.28 \\
\hline
\end{tabular}


Table 1 (continued)

\begin{tabular}{|l|l|l|}
\hline Diabetes & 20 & 17.54 \\
\hline Psychiatry illness & 3 & 2.63 \\
\hline Respiratory disease & 20 & 17.54 \\
\hline Gastrointestinal disorders & 1 & 0.88 \\
\hline Seizure disorder & 2 & 1.75 \\
\hline Cancer & 1 & 0.88 \\
\hline Stroke (previous history) & 5 & 4.38 \\
\hline Dementia & 6 & 5.26 \\
\hline Previous head injury & 2 & 1.75 \\
\hline
\end{tabular}

Abbreviations: GCS, Glasgow coma scale; RTA, road traffic accident.

Table 2 Site, side and CT findings of aSDH

\begin{tabular}{|c|c|c|}
\hline Site & $\begin{array}{l}\text { Number of } \\
\text { patients }\end{array}$ & $\%$ \\
\hline Fronto-temporo-parietal & 92 & 80.70 \\
\hline Posterior fossa & 4 & 3.52 \\
\hline Temporoparietal & 3 & 2.63 \\
\hline Frontotemporal & 9 & 7.89 \\
\hline Temporal & 2 & 1.75 \\
\hline Parietal & 1 & 0.88 \\
\hline Frontoparietal & 3 & 2.63 \\
\hline \multicolumn{3}{|l|}{ Side of aSDH } \\
\hline Left & 65 & 57 \\
\hline Right & 49 & 43 \\
\hline \multicolumn{3}{|l|}{ CT findings } \\
\hline \multicolumn{3}{|l|}{ Clot thickness (mm) } \\
\hline$<10$ & 2 & 1.75 \\
\hline $10-15$ & 28 & 24.56 \\
\hline $15-20$ & 49 & 42.98 \\
\hline$\geq 20$ & 35 & 30.70 \\
\hline MLS > $5 \mathrm{~mm}$ & 105 & 92.10 \\
\hline Herniation & 66 & 57.89 \\
\hline
\end{tabular}

Abbreviations: aSDH, acute subdural hematoma; MLS, midline shift.

\section{Variables of Operated Acute SDH cases - Glasgow Outcome Scale Categories (1-3 versus $4-5$ )}

On evaluating dichotomized outcome classified in death/ dependent (1-3) versus independent (4-5), we found significant association of age $(p=0.0089)$, best motor response $(p<0.0001)$, pupillary changes $(p<0.0001)$, severity of injury $(p<0.0001)$, and GCS at admission with outcome following
Table 3 GOS

\begin{tabular}{|l|l|l|}
\hline GOS & $\begin{array}{l}\text { Number of } \\
\text { patients }\end{array}$ & $\%$ \\
\hline 5 (good recovery) & 30 & 26.32 \\
\hline $\begin{array}{l}4 \text { (moderate } \\
\text { disability) }\end{array}$ & 24 & 21.05 \\
\hline 3 (severe disability) & 23 & 20.17 \\
\hline $\begin{array}{l}2 \text { (persistent } \\
\text { vegetative state) }\end{array}$ & 25 & 21.93 \\
\hline 1 (Dead) & 12 & 10.53 \\
\hline
\end{tabular}

Abbreviation: GOS, Glasgow outcome scale.

surgery. Gender and mode of injury were not significantly associated (-Table 5)

\section{Discussion}

This study included only operated cases of acute SDH. The most common age group operated upon in this study was 40 to 60 years ( $n=45,39.48 \%$ ), closely followed by 20 to 40 years ( $n=41,35.96 \%$ ), thus affecting the most productive working population. Acute SDH is more common in geriatric patients due to age-related cerebral atrophy, increased subdural space, stretching of bridging veins, and higher risk for trauma due to gait or orthopedic-related problems. ${ }^{7,8}$ As the age of population increases, acute SDH also increases in its frequency. ${ }^{9}$

In this study, males ( $n=89,78 \%$ ) were affected more than females $(n=25,22 \%)$ with male is to female ratio of 3.56:1. Studies in operated acute SDH have shown male predominance. ${ }^{10}$ It may be attributable to our social culture in which most of the females are nonworking and so are not susceptible to external works.

In this study, RTA ( $n=93,81.58 \%$ ) was the most common mode of injury. Studies with comatose patients have demonstrated RTA as the mechanism of injury in most acute SDH cases. ${ }^{11}$ Most acute SDHs are caused by RTA and falls. ${ }^{12}$ Frequency of other mechanisms is very less. RTA is 
Table 4 Variables of operated aSDH cases-GOS

\begin{tabular}{|c|c|c|c|c|c|c|}
\hline Characteristics & $1(n=12)$ & $2(n=25)$ & $3(n=23)$ & $4(n=24)$ & $5(n=30)$ & $p$-Value \\
\hline Age & $\begin{array}{l}49.83 \\
(12.22)\end{array}$ & $\begin{array}{l}50.52 \\
(13.68)\end{array}$ & $\begin{array}{l}48.48 \\
(11.88)\end{array}$ & $\begin{array}{l}44.5 \\
(17.40)\end{array}$ & $\begin{array}{l}40.42 \\
(16.55)\end{array}$ & 0.0926 \\
\hline \multicolumn{6}{|l|}{ Gender (\%) } & \multirow[t]{3}{*}{0.1966} \\
\hline Male & $9(75 \%)$ & $18(72 \%)$ & $16(69.56 \%)$ & $23(95.83 \%)$ & $23(76.67 \%)$ & \\
\hline Female & $3(25 \%)$ & $7(28 \%)$ & $7(30.44 \%)$ & $1(4.17 \%)$ & $7(23.33 \%)$ & \\
\hline \multicolumn{7}{|l|}{ Mode of injury } \\
\hline $\begin{array}{l}\text { RTA } \\
\text { FFH } \\
\text { Assault } \\
\text { Spontaneous }\end{array}$ & $\begin{array}{l}10(83.34 \%) 0 \\
1(8.33 \%) \\
1(8.33 \%)\end{array}$ & $\begin{array}{l}20(80 \%) \\
4(16 \%) \\
1(4 \%) \\
0\end{array}$ & $\begin{array}{l}18(78.26 \%) \\
5(21.74 \%)\end{array}$ & $\begin{array}{l}19(79.16 \%) \\
3(12.5 \%) \\
1(4.17 \%) \\
1(4.17 \%)\end{array}$ & $\begin{array}{l}26(86.67 \%) \\
3(10 \%) \\
1(3.33 \%)\end{array}$ & 0.5995 \\
\hline Best motor response & $\begin{array}{l}1.75 \\
(0.62)\end{array}$ & $\begin{array}{l}2.24 \\
(0.60)\end{array}$ & $\begin{array}{l}3.13 \\
(0.62)\end{array}$ & $\begin{array}{l}3.67 \\
(0.82)\end{array}$ & $\begin{array}{l}4.93 \\
(0.52)\end{array}$ & $<0.0001$ \\
\hline Pupillary changes & $12(100 \%)$ & $24(96 \%)$ & $10(43.47)$ & $2(8.33 \%)$ & 0 & $<0.0001$ \\
\hline Severity of injury & & & & & & $<0.0001$ \\
\hline Mild & 0 & 0 & 0 & 0 & $7(23.33 \%)$ & \\
\hline Moderate & 0 & 0 & 0 & $2(8.33 \%)$ & $19(63.34 \%)$ & \\
\hline Severe & $12(100 \%)$ & $25(100 \%)$ & $23(100 \%)$ & $22(91.67 \%)$ & $4(13.33 \%)$ & \\
\hline GCS at admission & $\begin{array}{l}3.75 \\
(0.62)\end{array}$ & $\begin{array}{l}4.52 \\
(0.96)\end{array}$ & $\begin{array}{l}5.69 \\
(1.06)\end{array}$ & $\begin{array}{l}6.71 \\
(1.90)\end{array}$ & $\begin{array}{l}11 \\
(2.49)\end{array}$ & $<0.0001$ \\
\hline
\end{tabular}

Abbreviations: aSDH, acute subdural hematoma; GCS, Glasgow outcome scale; FFH, fall from height; RTA, road traffic accident.

aStatistically significant $(<0.05)$.

Table 5 Variables of operated aSDH cases-GOS categories (1-3 versus 4-5)

\begin{tabular}{|c|c|c|c|}
\hline Characteristics & $1-3(n=60)$ & $4-5(n=54)$ & $p$-Value \\
\hline Age & $\begin{array}{l}49.6 \\
(12.55)\end{array}$ & $\begin{array}{l}42.23 \\
(16.89)\end{array}$ & $0.0089^{a}$ \\
\hline Gender (\%) & & & \multirow[t]{2}{*}{0.0815} \\
\hline $\begin{array}{l}\text { Male } \\
\text { Female }\end{array}$ & $\begin{array}{l}43(71.67 \%) \\
17(28.33 \%)\end{array}$ & $\begin{array}{l}46(85.18 \%) \\
8(14.82 \%)\end{array}$ & \\
\hline Mode of injury & & & \multirow[t]{2}{*}{0.9439} \\
\hline $\begin{array}{l}\text { RTA } \\
\text { FFH } \\
\text { Assault } \\
\text { Spontaneous }\end{array}$ & $\begin{array}{l}48(80 \%) \\
9(15 \%) \\
2(3.33 \%) \\
1(1.67 \%)\end{array}$ & $\begin{array}{l}45(83.33 \%) \\
6(11.12 \%) \\
2(3.70 \%) \\
1(1.85 \%)\end{array}$ & \\
\hline Best motor response & $\begin{array}{l}2.48 \\
(0.81)\end{array}$ & $\begin{array}{l}4.37 \\
(0.92)\end{array}$ & $<0.0001^{a}$ \\
\hline Pupillary changes & $46(76.67 \%)$ & $2(3.70 \%)$ & $<0.0001^{\mathrm{a}}$ \\
\hline Severity of injury & & & \multirow[t]{2}{*}{$<0.0001^{\mathrm{a}}$} \\
\hline $\begin{array}{l}\text { Mild } \\
\text { Moderate } \\
\text { Severe }\end{array}$ & $\begin{array}{l}0 \\
0 \\
60(100 \%)\end{array}$ & $\begin{array}{l}7(12.96 \%) \\
21(38.89 \%) \\
26(48.15 \%)\end{array}$ & \\
\hline GCS at admission & $\begin{array}{l}4.82 \\
(1.20)\end{array}$ & $\begin{array}{l}9.09 \\
(3.10)\end{array}$ & $<0.0001^{\mathrm{a}}$ \\
\hline
\end{tabular}

Abbreviations: aSDH, acute subdural hematoma; GCS, Glasgow outcome scale; FFH, fall from height; RTA, road traffic accident.

aStatistically significant $(<0.05)$.

most frequent in the 15 to 30 years age group. Injury due to falls is most frequent in the 45 to 80 years age group. ${ }^{13}$

Most of the operated cases of acute SDH were severe (GCS 3-8) in traumatic brain injury (TBI) severity scale $(n=86,75.44 \%)$. M2 $(n=30,26.32 \%)$ was the most common best motor response in this study. It is similar to earlier studies having $35 \%$ to $80 \%$ of patients with acute SDH, presenting with GCS score of 8 or less. ${ }^{14,15}$

The most common clinical presentation was altered sensorium ( $n=112,98.25 \%$ ), followed by headache/vomiting ( $n=32,28.07 \%$ ) which may be attributed to poor GCS score and raised ICP due to acute SDH mass effect and secondary brain injury. 
The most common site of operated acute SDH cases was frontotemporoparietal region $(n=92,80.70 \%)$ with left side predilection ( $n=65,57 \%$ ). It is usually hemispheric over convexity of brain. In this study, clot thickness of 15 to $20 \mathrm{~mm}$ ( $n=49,42.98 \%$ ) was found most commonly. Most of the operated cases had a midline shift $(n=105,92.10 \%)$ and herniation ( $n=66,57.89 \%$ ) before surgery.

The most common comorbidity associated with operated acute SDH was hypertension ( $n=32,28.07 \%$ ). Hypertension, as the most common comorbidity in acute $\mathrm{SDH}$, is also seen in other study. ${ }^{16}$

In this study, a GOS score of 5 was most common ( $n=30$, $26.32 \%)$, followed by a GOS score of 2 ( $n=25,21.93 \%)$. There were $12(10.53 \%)$ mortalities in this study. Many studies had shown mortality between 30 to $60 \%$ in acute SDH patients with a GCS score of 3-15 ${ }^{17,18}$ or mortality between 55 to $70 \%$ with a GCS score of 8 or less. ${ }^{11,19}$ However, a GOS score of 2 (persistent vegetative state) was present in $21.93 \%(n=25)$, showing high-morbidity rate in this study.

On analyzing variables on GOS, we found that GCS at admission, severity of injury, pupillary changes, and best motor response were significantly $(p<0.05)$ associated with outcome following surgery for acute SDH. In contrast, age and gender of patients were not found to be significantly associated with outcome following surgery. Studies had shown that patient with age more than 65 years are associated with poorer outcomes. ${ }^{19}$

Studies have shown gender influence on prognosis in TBI. ${ }^{20}$ Poorer outcome had been reported in females surviving severe TBI when compared with males. ${ }^{21}$ In this study, gender is not associated with poor outcome in the GOS or dichotomized analysis.

Acute SDH due to spontaneous mechanism of injury was a poor prognostic factor in various studies. Oral anticoagulation therapy and disorders of bleeding diathesis are the most common causes related to spontaneous aSDH. ${ }^{22-24}$

Nevertheless, a reliable GCS score may be hard to get in acute situations, according to medical sedation, paralysis and/or intoxication. ${ }^{25}$ Motor response is the most reproductive element in trauma patients, as the other responses may be blunt. ${ }^{26}$ Keeping these limitations in mind, the GCS in this study was evaluated at the time of hospital admission. GCS at admission was significantly associated with outcome in both GOS and dichotomized analysis.

Pupillary reactivity changes or abnormalities reflect brainstem compression or lesion and are indicative of poorer outcome. ${ }^{27}$ Many studies have shown that pupillary reactivity when compared with GCS is more reliable after TBI, as it is less effected by sedation and paralysis ${ }^{28}$

However, on analyzing dichotomized outcome, namely, death/dependent (1-3) versus independent (4-5), we found that, in addition to above mentioned variables, age was also significantly $(p<0.05)$ associated with outcome following surgery.

Some studies recommend prompt evacuation of acute SDH with indications for surgery, as this reduces brain damage resulting from secondary ischemic injury, due to mass effect and/or raised ICP., ${ }^{5,29,30}$ However, most studies done to evaluate correlation between early surgery and outcome have not shown a correlation with outcome. ${ }^{11,14,18,31,32}$

Cognitive and neurological changes following large craniectomy have been attributed to many factors including atmospheric pressure, venous return obstruction, cerebral blood flow, metabolic changes and cerebrospinal fluid (CSF) changes. There is reduction in cerebral blood flow due to atmospheric pressure and reduced cerebral metabolic rate. ${ }^{33}$ This may certainly affect the outcome, producing a bias in the presented results. ${ }^{33,34}$

\section{Conclusion}

Acute SDH is a frequent neurosurgical condition responsible for significant morbidity and mortality. It affects the working productive age group (20-60 years), with males more affected than females. The most common associated comorbidity was hypertension. RTA was the most common mode of injury. Altered sensorium is the most common clinical presentation. It most commonly affects the frontotemporoparietal region, with greater predilection to the left side. GCS at admission, severity of injury, pupillary changes, and best motor response were significantly ( $p<0.05$ ) associated with outcome following surgery for acute SDH. In contrast, age and gender of patients were not found to be significantly associated with outcome following surgery. However, when comparing dichotomized outcome, death/dependent (1-3) versus independent (4-5), age was also significantly $(p<0.05)$ associated with outcome following surgery.

\section{Funding}

None.

\section{Conflict of Interest}

None declared.

\section{References}

1 Youmans J, Winn H, Youmans \& Winn Neurological Surgery. 7th ed. Philadelphia: Elsevier; 2017

2 Marshall LF, Gautille R, Klauber MR, et al. The outcome of severe closed head injury. J Neurosurg 1991;75(suppl) :S28-S36

3 Kawamata T, Takeshita M, Kubo O, Izawa M, Kagawa M, Takakura K. Management of intracranial hemorrhage associated with anticoagulant therapy. Surg Neurol 1995;44(5):438-442, discussion 443

4 Marbacher S, Fandino J, Lukes A. Acute subdural hematoma from ruptured cerebral aneurysm. Acta Neurochir (Wien) 2010;152(3):501-507

5 Seelig JM, Becker DP, Miller JD, Greenberg RP, Ward JD, Choi SC. Traumatic acute subdural hematoma: major mortality reduction in comatose patients treated within four hours. N Engl J Med 1981;304(25):1511-1518

6 Seelig JM, Greenberg RP, Becker DP, Miller JD, Choi SC. Reversible brain-stem dysfunction following acute traumatic subdural hematoma: a clinical and electrophysiological study. J Neurosurg 1981;55(4):516-523

7 Hanif S, Abodunde O, Ali Z, Pidgeon C. Age related outcome in acute subdural haematoma following traumatic head injury. Ir Med J 2009;102(8):255-257 
8 Petridis AK, Dörner L, Doukas A, Eifrig S, Barth H, Mehdorn M. Acute subdural hematoma in the elderly; clinical and CT factors influencing the surgical treatment decision. Cent Eur Neurosurg 2009;70(2):73-78

9 Kameyama M, Karibe H, Kawase M, Hayashi T, Hirano T, Tominaga T. Severe head injury and age in Japan Neurotrauma Data Bank: comparison among Project 1998, 2004, 2009. ] Neurotraumatology 2013;36:10-16

10 Ryan CG, Thompson RE, Temkin NR, Crane PK, Ellenbogen RG, Elmore JG. Acute traumatic subdural hematoma: current mortality and functional outcomes in adult patients at a Level I trauma center. J Trauma Acute Care Surg 2012;73(5):1348-1354

11 Kotwica Z, Brzeziński J. Acute subdural haematoma in adults: an analysis of outcome in comatose patients. Acta Neurochir (Wien) 1993;121(3-4):95-99

12 Sawauchi S, Murakami S, Ogawa T, Abe T. [Acute subdural hematoma associated with diffuse brain injury: analysis of 526 cases in Japan neurotrauma data bank]. No Shinkei Geka 2007;35(1):43-51

13 Kameyama M, Karibe H, Onuma T, Tominaga T. Epidemiological study of head injury in Miyagi neurotrauma databank: age, cause of injury, pathophysiology and outcome. Neurotraumatology 2008;31:49-56

14 Massaro F, Lanotte M, Faccani G, Triolo C. One hundred and twenty-seven cases of acute subdural haematoma operated on. Correlation between CT scan findings and outcome. Acta Neurochir (Wien) 1996;138(2):185-191

15 van den Brink WA, Zwienenberg M, Zandee SM, van der Meer L, Maas AI, Avezaat CJ. The prognostic importance of the volume of traumatic epidural and subdural haematomas revisited. Acta Neurochir (Wien) 1999;141(5):509-514

16 Mulligan P, Raore B, Liu S, Olson JJ. Neurological and functional outcomes of subdural hematoma evacuation in patients over 70 years of age. J Neurosci Rural Pract 2013;4(3):250-256

17 Umezawa K, Kimura S, Ogita S, Takegami T, Ikeda E. Analysis of 469 cases of acute subdural hematoma: the characteristics of "talk and deteriorate" patients. Neurotraumatology 2011;34:132-138

18 Koç RK, Akdemir H, Oktem IS, Meral M, Menkü A. Acute subdural hematoma: outcome and outcome prediction. Neurosurg Rev 1997;20(4):239-244

19 Wilberger JE Jr, Harris M, Diamond DL. Acute subdural hematoma: morbidity, mortality, and operative timing. J Neurosurg 1991;74(2):212-218

20 Maas AI, Murray GD, Roozenbeek B, et al; International Mission on Prognosis Analysis of Clinical Trials in Traumatic Brain Injury (IMPACT) Study Group. Advancing care for traumatic brain injury: findings from the IMPACT studies and perspectives on future research. Lancet Neurol 2013;12(12):1200-1210

21 Farace E, Alves WM. Do women fare worse: a metaanalysis of gender differences in traumatic brain injury outcome. J Neurosurg 2000;93(4):539-545
22 Jeffree RL, Gordon DH, Sivasubramaniam R, Chapman A. Warfarin related intracranial haemorrhage: a case-controlled study of anticoagulation monitoring prior to spontaneous subdural or intracerebral haemorrhage. J Clin Neurosci 2009;16(7):882-885

23 Basmaci M, Hasturk AE. Chronic subdural hematoma in a child with acute myeloid leukemia after leukocytosis. Indian J Crit Care Med 2012;16(4):222-224

24 Fryburg K, Nguyen HS, Cohen-Gadol AA. Spontaneous acute subdural hematoma due to fondaparinux: Report of two cases. Surg Neurol Int 2011;2:44

25 Stocchetti N, Pagan F, Calappi E, et al. Inaccurate early assessment of neurological severity in head injury. J Neurotrauma 2004;21(9):1131-1140

26 Marmarou A, Lu J, Butcher I, et al. Prognostic value of the Glasgow Coma Scale and pupil reactivity in traumatic brain injury assessed pre-hospital and on enrollment: an IMPACT analysis. J Neurotrauma 2007;24(2):270-280

27 Chen SH, Chen Y, Fang WK, Huang DW, Huang KC, Tseng SH. Comparison of craniotomy and decompressive craniectomy in severely head-injured patients with acute subdural hematoma. J Trauma 2011;71(6):1632-1636

28 Marmarou A, Lu J, Butcher I, et al. IMPACT database of traumatic brain injury: design and description. J Neurotrauma 2007;24(2):239-250

29 Shima, K, Aruga, T, Onuma, T, Shigemori, M; Members of the Japanese Guidelines Committee on the Management of Severe Head Injury (2nd Edition). Japan Society of Neurotraumatology. JSNT-Guidelines for the Management of Severe Head Injury (abridged edition) Asian J Neurosurg 2010;5:15-23

30 Tien HC, Jung V, Pinto R, Mainprize T, Scales DC, Rizoli SB. Reducing time-to-treatment decreases mortality of trauma patients with acute subdural hematoma. Ann Surg 2011;253(6):1178-1183

31 Servadei F, Nasi MT, Giuliani G, et al. CT prognostic factors in acute subdural haematomas: the value of the 'worst' CT scan. Br J Neurosurg 2000;14(2):110-116

32 Howard MA III, Gross AS, Dacey RG Jr, Winn HR. Acute subdural hematomas: an age-dependent clinical entity. J Neurosurg 1989;71(6):858-863

33 Oh CH, Park CO, Hyun DK, Park HC, Yoon SH. Comparative study of outcomes between shunting after cranioplasty and in cranioplasty after shunting in large concave flaccid cranial defect with hydrocephalus. J Korean Neurosurg Soc 2008;44(4):211-216

34 Schaller B, Graf R, Sanada Y, Rosner G, Wienhard K, Heiss WD. Hemodynamic and metabolic effects of decompressive hemicraniectomy in normal brain. An experimental PET-study in cats. Brain Res 2003;982(1):31-37 